\title{
Evaluation of Telomerase (hTert), Ki67 and p16ink4a expressions in low and high-grade cervical intraepithelial lesions
}

\author{
Avaliação da expressão de Telomerase (hTert), Ki67 e p16 ${ }^{\text {ink4a }}$ em lesões \\ intraepiteliais cervicais de baixo e alto graus
}

Ana Paula Szezepaniak Goulart"i; Manoel Afonso Guimarães Gonçalves'; Vinicius Duval da-Silva ${ }^{1}$.

A B S TR A C T

\begin{abstract}
Objective: to study the association between the histological grading of cervical intraepithelial neoplasia (CIN I, CIN II and CIN III) and the immunohistochemical expression for p16ink4a, hTert and Ki67, as well as to evaluate the relationship of these markers with the risk of recurrence after surgical treatment. Methods: we studied a historical cohort of 94 women with intraepithelial lesions CIN I (low grade), CIN II and CIN III (high grades) submitted to conization or electrosurgical excision of the transformation zone. We evaluated all surgical specimens for immunohistochemical expression of p16 ${ }^{\text {ink4a }}$, hTert and Ki67. Results: the mean age was 38.2 years; p16 ink4a was absent in most CIN I cases. In patients with CIN II or IIII (association of low and high-grade lesions), we observed p16 ink4a $\leq 10 \%$. In patients with CIN III, we found a higher expression frequency of $16^{\text {ink } 4 a}>50 \%$. In CIN I, the majority had Ki67 $\leq 10 \%$ and low frequency of Ki67>50\%. In the CIN III category, there were fewer patients with Ki67 $\leq 10 \%$, and Ki67 was absent in most patients of CIN II and III groups. There was no association between hTert expression and histologic grade. There were no statistically significant differences between the expression of the markers in patients with and without recurrence. Conclusion: there was a statistically significant association of p16 $6^{\text {ink4a }}$ and Ki67 with histological grade. The markers' expression, as for disease recurrence, was not statistically significant in the period evaluated.
\end{abstract}

Keywords: Cervical Intraepithelial Neoplasia. Telomerase. Immunohistochemistry. Recurrence.

\section{INTRODUCTION}

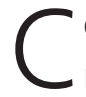
ervical cancer is the third most common malignant neoplasm among women (90\% of cases in developing countries), and in Brazil it accounts for $9.3 \%$ of gynecological malignancies. Worldwide, 500,000 new cases per year are diagnosed, accounting for 250,000 annual deaths ${ }^{1}$. The National Cancer Institute (INCA) recommends that cervical cytopathological screening be done every three years after two consecutive negative tests in patients aged 25 and 64 years, provided that the samples are satisfactory and representative of the squamous-column junction². The malignant neoplasm of the cervix is preceded by a long phase of precursor, usually asymptomatic, lesion, characterized by cervical intraepithelial neoplasia (CIN), which may persist for 10 to 20 years.

In 1976, Zur Hausen ${ }^{3}$ demonstrated the relationship between the HPV virus infection and the onset of genital tract neoplasias. Infection is more common in young patients; however, sexual behavior, age, smoking, parity and use of contraceptives are also risk factors for this neoplasia'. On the other hand, not all patients infected with the virus have the same disease progression, since this behavior is linked to environmental factors, immunity, host genetics and cellular factors ${ }^{4}$. The use of molecular markers has helped the pathologists in the definition of doubtful cases and in the identification of women at high risk for disease recurrence after treatment of cervical intraepithelial neoplasias ${ }^{5}$. p16 ink4a, a tumor suppressor protein, is overexpressed in cases of dysplasia, presenting a high sensitivity as it correlates with the dysplasia severity. Current studies indicate that $p 16^{\text {ink4a }}$ is a useful biomarker for high-risk lesions and for progression prediction in low-risk ones. These studies show a significant association between the degree of cervical lesion and the distribution and intensity of $\mathrm{p} 16^{\text {ink4a }}$ expression ${ }^{5,6}$.

1 - São Lucas Hospital, Pontifical Catholic University of Rio Grande do Sul (PUCRS), Gynecology and Pathology Service, Porto Alegre, Rio Grande do Sul State, Brazil. 
Ki67 is another cell proliferation marker expressed at all stages of the cell cycle, except in the G0 phase, and which, although not specifically involved in the cervical carcinogenic process, has an independent predictive value as to grading and evaluating disease progression?

Telomerase is a ribonucleic enzyme complex that allows telomere maintenance in $90 \%$ of cancer cases. In normal somatic cells, telomerase activity is low or undetectable, and telomeres shorten at each cell division. The hTert is the telomerase reverse transcriptase, being the most important factor in the formation of functional telomerase. The activation of telomerase establishes telomere length maintenance, acting in the transformation of dysplasia into malignant neoplastic alterations and in the maintenance of phenotypically more aggressive cell populations ${ }^{8}$. The hTert is present in $28.5 \%$ of CIN I, in $87.5 \%$ of CIN II and in $95 \%$ of CIN III'.

Among the existing treatments for the management of cervical intraepithelial neoplasias, in our hospital we perform the conization and the electrosurgical excision of the transformation zone (LEEP) techniques. The former has the advantage of allowing lesion resection and margins evaluating without the presence of fulguration artifacts by the passage of electric current, but removes a larger volume of cervical stroma, which can lead to adverse reproductive outcomes. The LEEP technique is a technically simpler procedure, which can be done in an outpatient setting under local anesthesia. On the other hand, margins may be inadequate for evaluation due to histological artifacts caused by thermal damage, have a higher risk of bleeding and may cause cervical stenosis in up to $6 \%$ of patients ${ }^{10}$. The literature recommends that patients'followup should be for at least one year with a cervical cytopathological exam (CP) and with semestral colposcopy after surgery, since this is the period of greatest risk of recurrence of cervical lesions ${ }^{11}$. The recurrence rate of high-grade intraepithelial lesions after surgical excision varies from $5 \%$ to $10 \% 4,12,13$.

The complication associated with the surgical treatment of such lesions are bleeding, external cervical orifice stenosis, infertility, shortening of the cervix and risk of preterm labor, isthmo-cervical incompetence, low birth weight fetuses, cesarean section and premature membranes rupture ${ }^{14}$. Therefore, to analyze the association between recurrence after surgical treatment and the expression of immunohistochemical markers according to the graduation of high and low grade intraepithelial lesions would allow the suspension of a rigorous clinical follow-up and the reduction of overdiagnosis and overtreatment in patients affected by this disease. To date, there is no description of the concomitant evaluation of the three immunohistochemical markers - p16ink4a, Ki67 and hTert - in high and low grade intraepithelial lesions. As already described, the only marker that has well established utility in the evaluation of progression, not recurrence, of these lesions is p16ink4a 15 . Other markers are still poorly studied and, therefore, there are few published papers regarding Ki67 and hTert, with no established accuracy for use in clinical practice, although they appear to display a difference according to their expression between high and low grade lesions ${ }^{16}$. Furthermore, the behavior of CIN II is still uncertain, and so far, this lesion receives the same treatment as CIN III, a standardized conduct based on the 1991 Bethesda consensus ${ }^{17}$. However, in recent years, its aggressiveness has been questioned, since it behaves dubiously, with a significant number of cases showing good evolution, spontaneous regression or indolent behavior ${ }^{6,7}$. The establishment of recurrence risk markers for this type of lesion is thus innovative, and could define which patients would require surgical treatment and which would be likely to remain in clinical follow-up. This answer does not yet exist in the literature.

\section{METHODS}

We studieda historical cohort in which we analyzed 94 patients divided into three groups with cervical intraepithelial lesions, CIN I, CIN II and CIN III, submitted to conization or LEEP. We followed the patients for two years to determine disease recurrence. The sample consisted of patients from the Gynecology outpatient clinic of the São Lucas Hospital 
of the Pontifical Catholic University of Rio Grande do Sul (PUCRS), who underwent cervical cytopathological examination followed by colposcopy with biopsy of suspicious areas and subsequent diagnosis of CIN. We recruited patients by (consecutive) convenience sampling. All cases of the study had the histological examinations reviewed by a second pathologist with clinical experience superior to twenty years.

Inclusion criteria were patients aged 18 years or older, submitted to LEEP or conization, and with a six-month postoperative follow-up (cervical CP, colposcopy and cervix biopsy if necessary) for at least two years, whose surgical specimens had margins free of cervical intraepithelial neoplasia. Exclusion criteria were patients with human immunodeficiency virus (HIV) or other immunosuppressive disorders, and pregnancy.

We performed the immunohistochemistry technique on tissues fixed in formalin and included in paraffin. The detection method used for screening tissue antigens was avidin-biotin peroxidase. We produced $3-\mu \mathrm{m}$ thick histological sections on a Leica RT2150 rotary microtome. The slides were deparaffinized in a histological oven at $69^{\circ} \mathrm{C}$, two incubations in xylol, five incubations with $99^{\circ}$ ethyl alcohol, washing in running water until complete removal and then maintained in a PBS buffer. Antigen retrieval utilized a 6.0-pH citrate buffer for 20 minutes. Endogenous peroxidase activity was blocked with $5 \%$ hydrogen peroxide solution in methyl alcohol. Incubation with the primary antibody was performed in a $\mathrm{BOD}$ incubator at $5^{\circ} \mathrm{C}$. To detect the antigenantibody reaction, we used biotinylated secondary antibody and avidin-HRP complex. We performed staining with Diamine Benzidine (DAB, DAKO) as the chromogen. Finally, we counterstained the slides with Harris haematoxylin, dehydrated in a series of $99^{\circ}$ ethyl alcohol, clarified in xylene and mounted with Canadian balsam. The clones used for the markers were $\mathrm{E} 6 \mathrm{H} 4$ to p16ink4a, MM1 to Ki67 and 2C4 to hTert. For the detection of p16 ink4a , Ki67 and hTert, we used slides without cervical intraepithelial neoplasia as negative controls and, as positive controls, slides with high cervical intraepithelial neoplasia (CIN III). Regarding the interpretation of the markers, we considered the nuclear staining as positive for the cells expressing p16ink4a. We graded the expression intensity for p16 ink4a in CIN as negative if none of the cells displayed staining, and as positive, if they expressed staining as a percentage (less than 10\%, $11 \%$ to $50 \%$ or more than $50 \%$ ). We considered Ki67 positive only if the nuclei of the cells showed staining and we determined the percentage of cells expressing it in less than $10 \%, 11 \%$ to $50 \%$ or more than $50 \%$. We considered hTert positive also if the cell nucleus was stained. The expression was considered positive if the cells expressed staining and negative when there was no expression.

We inputted the data in the Excel 2010 software and later exported to the SPSS v.20.0 program for statistical analysis. We described categorical variables by frequencies and percentages and analyzed them with the Chi-square test. We described the quantitative variables with symmetrical distribution by the mean and standard deviation, comparing two categories with the Student $t$ test for independent samples, and three categories or more, with the Analysis of Variance (ANOVA) test. We described quantitative variables with asymmetric distribution by median and the interquartile range (25th and 75th percentiles), comparing two categories with the Mann-Whitney test, and three or more categories, with the Kruskal-Wallis test. We set the significance level at 5\%.

The project was approved by the Scientific Committee of the Postgraduate Program in Medicine and Health Sciences and by the Ethics Committee / PUCRS (protocol no. 109403/2014).

\section{RESULTS}

Patients' mean age was 38 years, with a standard deviation of $11.7 ; 37 \%$ used combined oral contraceptives and $26 \%$ did not use any contraceptive method. Only $31 \%$ were smokers, the mean number of children was two and the average of the first intercourse was at 16 years. The surgical approach was conization in $79.8 \%$ of patients. The most frequent anatomic and pathological findings were CIN III (52\%), followed by CIN I (14.9\%) and 
Table 1. Histological grade and the expression of Immunohistochemistry markers

\begin{tabular}{|c|c|c|c|c|c|}
\hline & CIN I & CIN I/II and II & CIN III & CIN II and III & $P$ \\
\hline p16 $6^{\text {ink4a }}$ & & & & & 0.026 \\
\hline$\leq 10$ & $3(23.1)$ & $5(38.5)$ & $8(16.7)$ & - & \\
\hline $11-50$ & - & $1(7.7)$ & $3(6.2)$ & $2(16.7)$ & \\
\hline$>50$ & $3(23.1)$ & $3(23.1)$ & $28(58.3)$ & $4(33.3)$ & \\
\hline Absent & $7(53.8)$ & $4(30.8)$ & $9(18.8)$ & $6(50.0)$ & \\
\hline Ki67 & & & & & 0.032 \\
\hline$\leq 10$ & $9(64.3)$ & $5(38.5)$ & $11(22.4)$ & $5(41.7)$ & \\
\hline $11-50$ & $3(21.4)$ & $1(7.7)$ & $9(18.4)$ & - & \\
\hline$>50$ & $2(14.3)$ & $7(53.8)$ & $27(55.1)$ & $5(41.7)$ & \\
\hline Absent & - & - & $2(4.1)$ & $2(16.7)$ & \\
\hline hTert & & & & & 0.677 \\
\hline Positive & $7(50.0)$ & 7 (53.8) & $30(62.5)$ & $5(45.5)$ & \\
\hline Negative & $7(50.0)$ & $6(46.2)$ & $18(37.5)$ & $6(54.5)$ & \\
\hline
\end{tabular}

Data presented by $n$ (\%) and compared with the Chi-square test. Data in bold are data whose adjusted residue had absolute value greater than 1.96. * High grade cervical intraepithelial lesion associated with the one of low grade.

CIN II (12.8\%). Among those who relapsed, most were carriers of CIN I, followed by carriers of CIN III.

The total number of recurrences among the 94 patients operated, regardless of the type of procedure, was 23 (24.5\%). Recurrence was more common in patients who underwent LEEP, 31\%, being $22 \%$ in those submitted to conization. There was a statistically significant association between p16 ink4a and Ki67 and histological grade, as shown in Table 1.

Figures 1, 2 and 3 show the expression of immunohistochemical markers.

There was no statistically significant difference between age, smoking, parity, age of first sexual intercourse and number of sexual partners and the different histological grades ordisease recurrence. When comparing the markers between subjects with and without recurrence, there were also no statistically significant differences.

\section{DISCUSSION}

Cervical carcinoma has a high potential for prevention. In our country, however, it is a public health problem.Studies have shown high incidence and mortality in developing countries, andgood control in developed countries whose screening programs are effective ${ }^{18}$.

Works have found that the immunohistochemical markers p16ink4a and Ki67 are more accurate in identifying precursor lesions in patients under 30 years with cervical cytopathological examination compatible with low grade intraepithelial lesion. The expression of these markers is associated with the severity of histological lesions. In the Possati-Resende et al. study ${ }^{18}$, patients underwent cervical biopsy,

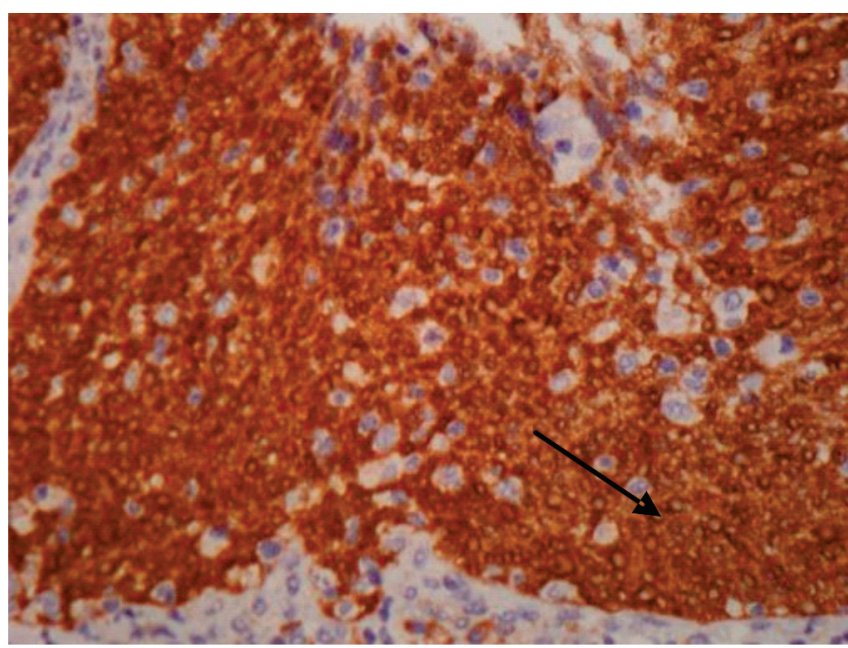

Figure 1. p16 ink4a, 200x magnification. Nuclear cells with marker expression in more than $50 \%$. 


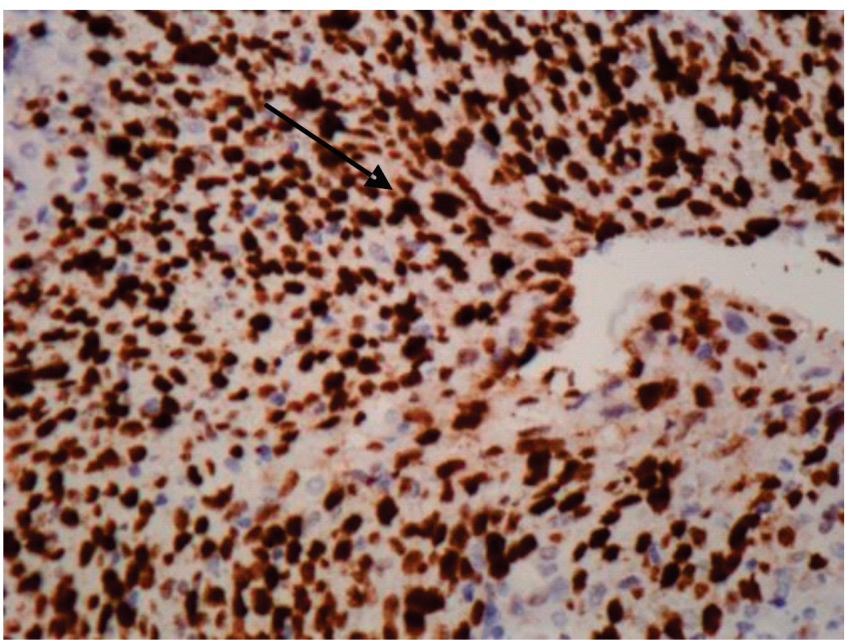

Figure 2. Ki67; 200x magnification. Nuclear cells with marker expression in more than 50\%.

and the expression of p16 ink4a and Ki67 was present in $46.5 \%$ of CIN I, $82.8 \%$ of CIN II and $92.8 \%$ of CIN III. In our study, p16 ${ }^{\text {ink4a }}$ was overexpressed by the immunohistochemical method in more than $50 \%$ of the cells of each sample in $43.3 \%$ of the cases, presenting a strong intensity in $48.9 \%$ of the exams. The Ki67 marker was expressed in $43.6 \%$ of the cases (positive in more than $50 \%$ of the sample). The hTert was positive in $56.5 \%$ of the cases studied.

Although the incidence of cervical neoplasms has decreased, there are still many diagnoses of cancer in cervical lesions with a high potential for regression and, consequently, of inadequate and excessive treatments. In this context, the use of immunohistochemical markers helps the pathologist in the histological evaluation of such lesions ${ }^{19}$. According to American guidelines, patients with suspected high-grade cervical intraepithelial neoplasia and overexpressed p16 ink4a benefit from surgical treatment. The positivity for this marker is linked to the onset of oncogenic transformation for the development of cancer and its use would allow the detection of pre-neoplastic lesions and the reduction of unnecessary aggressive treatments ${ }^{19}$.

The importance of studying these markers is due to the wide variability of interpretation among observers and the poor reproducibility of cytomorphological criteria, mainly regarding the use of hematoxylin and eosin for the histological diagnosis of cervical intraepithelial neoplasias, as well

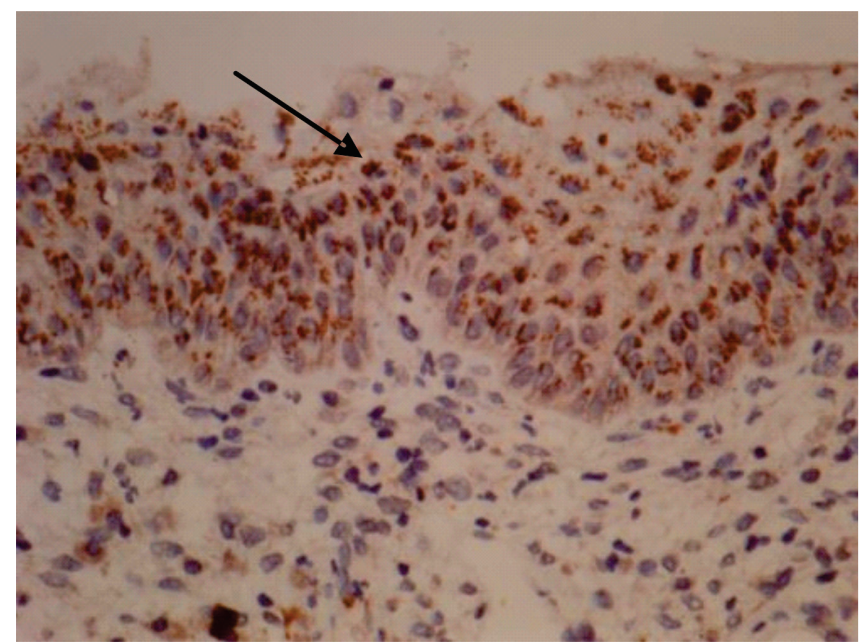

Figure 3. hTert; 200x magnification. Positivity in nuclear cells.

as its classification in the categoriesCIN I, II and III. We minimized this limitation in this study through the evaluation and concordance of diagnosis by two pathologists, one original interpreter of the case and one reviewer. The use of these markers complements the doubtful diagnoses, avoiding unnecessary treatments ${ }^{20,21}$. The presence of Ki67 in CIN I and CIN II in uterine cervix specimens is a strong independent predictive factor for graduation and disease progression, in addition to displaying an interobserver reproducibility of $100 \% 22$. The literature shows that the evaluated immunohistochemical markers, p16ink4a, Ki67 and hTert, are clearly associated with histological grade. Some studies have found an association with the risk of progression to high-grade neoplasias and cancer, but none showed that their overexpression is associated with recurrence after treatment.

The CIN recurrence rate usually ranges from $5 \%$ to $10 \%{ }^{4,12,13}$. However, in the study by Serati et al. ${ }^{23}$, who followed patients for ten years, recurrence occurred in $19.4 \%$ of the free-margin excisions and was twice as common with the LEEP technique. Although we included in our study only surgical pieces with free margins, the incidence of recurrence of $24.5 \%$ was high when compared with the rates described in the literature. On the other hand, Malapati et al. ${ }^{24}$ followed 717 eligible patients after LEEP and observed postoperative persistence/recurrence of $24.7 \%$. The most common type of recurrence was CIN I (47.8\%), followed by CIN III (34.8\%), and most occurred within 
the first six months after treatment (56\%).

There was no difference between the expression of the analyzed immunohistochemical markers and disease recurrence, even when evaluated individually at each histological grade. This fact may be due to the small number of cases and the subdivision of the markers expression positivity in below $10 \%, 11$ $50 \%$ and greater than 50\%, unlike other studies in which the quantitative analysis was made in absolute numbers, a method that still presents limitations for implementation in the surgical pathology diagnostic routine. The study by Cardoso et al. ${ }^{4}$ was one of the few that showed statistical significance between p16ink4a overexpression and disease recurrence, as did Nam et al. ${ }^{25}$. Fonseca et al. ${ }^{26}$ demonstrated that $\mathrm{p} 16^{\text {ink4a }}$ was overexpressed in $43 \%$ of the recurrences, with high intensity in 58\% of them, though this finding was not statistically significant. In a group of 90 patients with cervical intraepithelial neoplasia with overexpressed p16ink4a and Ki67, there was progression in 15 cases $(17 \%)$, two cases in the group of 25 patients with CIN I (8\%) and 13 cases in the group of 65 patients with CIN II $(20 \%)^{22}$. In our study, Ki67 expression was positive in $10 \%$ or less in CIN I and overexpressed in more than $50 \%$ of each sample in $53 \%$ of CIN II and $55 \%$ of CIN III $(p=0.032)$.

Age, smoking, number of children, age of first intercourse, and number of sexual partners showed no significant difference in disease recurrence. Contrary to our findings, the literature shows that age greater than or equal to 35 years and smoking are risk factors for recurrence, as well as larger cytological alterations, high-risk preoperative HPV infection, positive endocervical margins, and HIV infection $24,27,28$.

The expression of $p 16$ ink4a related significantly to the histological grade in this study. It was negative in $53 \%$ of CIN I, overexpressed in more than $50 \%$ of CIN III in 58\% of cases and expressed in a lower percentage (equal or less than 10\%) in $38.5 \%$ of the cases of CIN II ( $p=0.026)$. We observed a lower percentage of positivity for p16 ink4a in CIN II than in CIN III, although both overexpressed this marker with high intensity (53.8\% of CIN II and $62.5 \%$ of CIN III). In the study of Genovés ${ }^{6}$, evaluating 92 patients, p16 $6^{\text {ink4a }}$ was overexpressed in seven of the 54 patients with CIN I and in 17 of the 23 patients with CIN II. The study emphasizes that the diagnosis of CIN II should not rely solely on the positivity of this marker, and its absence does not imply lesionregression.

Regarding the risk of progression, a study evaluating 52 patients with CIN II showed disease regression in 28 cases, progression to CIN III in 13 and persistence of the lesion in 11 cases. In those who progressed, $91 \%$ of the lesions had overexpressed p16ink4a, with strong intensity ${ }^{29}$. As for hTert, the literature also describes its overexpression in highgrade intraepithelial lesions $(p<0.001)$ in $88 \%$ to $90 \%$ of the samples, while low-grade intraepithelial lesions have low expression in $94 \%$ of $\operatorname{cases}^{30}$. It can be inferred that the expression of this marker represents an early manifestation of the dysplastic process, therefore being overexpressed in $45 \%$ of CIN I, 70\% of CIN II and $80 \%(p=0.024)^{31}$. In our study, hTert did not show statistical significance in relation to the histological grade $(p=0.677)$, although it was positive in $62.5 \%$ of the $\mathrm{NCI} \mathrm{III,} 53.8 \%$ of CIN II and $50 \%$ of CIN I. Although the expression of immunohistochemical markers was positive in CIN II and CIN III, we observedvariable expression, showing a more intense and higher percentage of cells in high grade dysplasia. Such behavior of CIN II shows that this lesion probably has a behavior of lower aggressiveness when compared to CIN III. According to Wilkinson et al. ${ }^{32}$, the regression rate of CIN $\|$ is similar to that of CIN I in a follow-up of two years (17\% $12 \%)$. This poses a risk of overtreatment of such lesions, mainly in women under 25 years of age, since the risk of developing cervical cancer in untreated women with high-grade dysplasia is less than $1.5 \%$.

Despite the importance of the use of immunohistochemical markers in the progression of cervical intraepithelial neoplasias, also evidenced in our study, there was no association between the markers and the recurrence of dysplastic lesions. New studies are needed, as well as the prospection of new markers, to establish with better precision the characteristics of these lesions and to allow conservative management in those that present a more indolent behavior. 


\title{
R E S U M O
}

\begin{abstract}
Objetivo: estudar a associação entre a graduação histológica das neoplasias intraepiteliais cervicais (NIC I, NIC II e NIC III) e a expressão imuno-histoquímica para p16ink4a, hTert e Ki67, assim como, avaliar a relação destes marcadores com o risco de recorrência após tratamento cirúrgico. Métodos: estudo de coorte histórica de 94 mulheres portadoras de lesões intraepiteliais NIC I (baixo grau), NIC II e NIC III (altos graus), submetidas à conização ou à excisão eletrocirúrgica da zona de transformação. Todas as peças cirúrgicas foram avaliadas quanto à expressão imuno-histoquímica para p16 ink4a, hTert e Ki67. Resultados: a média de idade das pacientes foi 38,2 anos. Nas pacientes NIC I, a p16 ink4a estava ausente na maioria dos casos; nas pacientes NIC II ou l/II (associação de lesões de baixo e alto graus), observou-se frequência de p16ink4a $\leq 10 \%$. Nas pacientes NIC III, observou-se maior frequência de expressão de p16ink4a>50\%. Na categoria NIC I, a maioria apresentava Ki67 $\leq 10 \%$ e baixa frequência de Ki67>50\%. Na categoria NIC III houve menor número de pacientes com Ki67 $\leq 10 \%$, sendo que a maior parte das pacientes tinha Ki67 ausente nos grupos NIC II e III. Não houve associação entre a expressão do marcador imuno-histoquímico hTert e a graduação histológica. Não houve diferenças estatisticamente significativas entre as expressões dos marcadores em pacientes com e sem recorrência. Conclusão: houve associação estatisticamente significativa apenas de p16 ink4a e Ki67 com a graduação histológica. A expressão dos marcadores em relação à recorrência da doença não foi estatisticamente significativa no período avaliado.
\end{abstract}

Descritores: Neoplasia Intraepitelial Cervical. Telomerase. Imuno-Histoquímica. Recidiva.

\section{REFERENCES}

1. Wise J. Pilot study will assess whether HPV test should replace smears to screen for cervical cancer. BMJ. 2012;344:e3744.

2. Ministério da Saúde. Instituto Nacional de Câncer. Diretrizes brasileiras para o rastreamento do câncer do colo do útero. Rio de Janeiro: INCA; 2011.

3. zur Hausen H. Condylomata acuminata and human genital cancer. Cancer Res. 1976;36(2 Pt 2):794.

4. Cardoso FA, Campaner AB, Silva MA. Prognostic value of p16(INK4a) as a marker of clinical evolution in patients with cervical intraepithelial neoplasia grade 3 (CIN 3) treated by cervical conization. APMIS. 2014;122(3):192-9.

5. Yildiz IZ, Usubütün $A$, Firat $P$, Ayhan $A$, Küçükali $T$. Efficiency of immunohistochemical p16 expression and HPV typing in cervical squamous intraepithelial lesion grading and review of the p16 literature. Pathol Res Pract. 2007;203(6):445-9.

6. Genovés J, Alameda F, Mancebo G, Solé JM, Bellosillo $B$, Lloveras $B$, et al. Human papillomavirus detection and p16INK4a expression in cervical lesions: a comparative study. Hum Pathol. 2014;45(4):826-33.

7. Martin CM, O'Leary JJ. Histology of cervical intraepithelial neoplasia and the role of biomarkers. Best Pract Res Clin Obstet Gynaecol. 2011;25(5):605-15.

8. Hsu CG, Wang PH, Ko JL, Chen GD, Chang H, Yang $\mathrm{SF}$, et al. Concurrent high expression of human telomerase reverse transcriptase and human nonmetastatic clone 23 in high-grade squamous intraepithelial neoplasia and squamous cell carcinoma of ute- rine cervix. Int J Gynecol Cancer. 2007;17(4):851-7.

9. Saha B, Chaiwun B, Tsao-Wei DD, Groshen SL, Naritoku WY, Atkinson RD, et al. Telomerase and markers of cellular proliferation are associated with the progression of cervical intraepithelial neoplasia lesions. Int J Gynecol Pathol. 2007;26(3):214-22.

10. Lindeque BG. Management of cervical premalignant lesions. Best Pract Res Clin Obstet Gynaecol. 2005;19(4):545-61.

11. Massad LS. Preinvasive disease of the cervix. In: Di Saia PJ, Creasman WT, Mannel RS, McMeekin DS, Mutch DG, editors. Clinical gynecologic oncology. $8^{\text {th }}$ ed. Philadelphia: Elsevier; 2012. p. 1-30.

12. Sarian LO, Derchain SF, Andrade LA, Tambascia J, Morais SS, Syrjänen KJ. HPV DNA test and Pap smear in detection of residual and recurrent disease following loop electrosurgical excision procedure of high-grade cervical intraepithelial neoplasia. Gynecol Oncol. 2004;94(1):181-6.

13. Prato B, Ghelardi A, Gadducci A, Marchetti I, Di Cristofano C, Di Coscio G, et al. Correlation of recurrence rates and times with posttreatment human papillomavirus status in patients treated with loop electrosurgical excision procedure conization for cervical squamous intraepithelial lesions. Int J Gynecol Cancer. 2008;18(1):90-4.

14. Kyrgiou M, Koliopoulos G, Martin-Hirsch P, Arbyn M, Prendiville W, Paraskevaidis E. Obstetric outcomes after conservative treatment for intraepithelial or early invasive cervical lesions: systematic review and meta-analysis. Lancet. 2006;367(9509):489-98. 
15. Darragh TM, Colgan TJ, Thomas Cox J, Heller DS Henry MR, Luff RD, et al. The Lower Anogenital Squamous Terminology Standardization project for HPV-associated lesions: background and consensus recommendations from the College of American Pathologists and the American Society for Colposcopy and Cervical Pathology. Int J Gynecol Pathol. 2013;32(1):76-115. Erratum in: Int J Gynecol Pathol. 2013;32(4):432. Int J Gynecol Pathol. 2013;32(2):241.

16. Fujii $T$, Saito $M$, Hasegawa $T$, Iwata T, Kuramoto $H$, Kubushiro $K$, et al. Performance of p16INK4a/Ki-67 immunocytochemistry for identifying CIN2+ in atypical squamous cells of undetermined significance and low-grade squamous intraepithelial lesion specimens: a Japanese Gynecologic Oncology Group study. Int J ClinOncol. 2015;20(1):134-42.

17. Solomon D, Nayar R. Sistema Bethesda para citopatologia cervicovaginal. 2a ed. Rio de Janeiro: Revinter; 2005.

18. Possati-Resende JC, Fregnani JH, Kerr LM, Mauad EC, Longatto-Filho A, Scapulatempo-Neto C. The Accuracy of p16/Ki-67 and HPV Test in the Detection of CIN2/3 in Women Diagnosed with ASC-US or LSIL. PLoS One. 2015;10(7):e0134445.

19. Pacchiarotti A, Galeotti S, Bellardini P, Chini F, Collina G, Dalla Palma $P$, et al. Impact of p16(INK4a) immunohistochemistry staining on interobserver agreement on the diagnosis of cervical intraepithelial neoplasia. Am J Clin Pathol. 2014;141(3):367-73.

20. Calil LN, Edelweiss MI, Meurer L, Igansi CN, Bozzetti MC. p16 INK4a and Ki67 expression in normal, dysplastic and neoplastic uterine cervical epithelium and human papillomavirus (HPV) infection. Pathol Res Pract. 2014;210(8):482-7.

21. Walts $A E$, Bose S. p16, Ki-67, and BD ProExC immunostaining: a practical approach for diagnosis of cervical intraepithelial neoplasia. Hum Pathol. 2009;40(7):957-64.

22. Kruse AJ, Baak JP, Janssen EA, Kjellevold KH, Fiane $B$, Lovslett $K$, et al. Ki67 predicts progression in early CIN: validation of a multivariate progression-risk model. Cell Oncol. 2004;26(1-2):13-20.
23. Serati M, Siesto G, Carollo S, Formenti G, Riva C, Cromi $A$, et al. Risk factors for cervical intraepithelial neoplasia recurrence after conization: a 10-year study. Eur J Obstet Gynecol Reprod Biol. 2012;165(1):86-90.

24. Malapati R, Chaparala S, Cejtin HE. Factors influencing persistence or recurrence of cervical intraepithelial neoplasia after loop electrosurgical excision procedure. J Low Genit Tract Dis. 2011;15(3):177-9.

25. Nam EJ, Kim JW, Hong JW, Jang HS, Lee SY, Jang SY, et al. Expression of the p16 and Ki-67 in relation to the grade of cervical intraepithelial neoplasia and high-risk human papillomavirus infection. J Gynecol Oncol. 2008;19(3):162-8.

26. Fonseca FV, Tomasich FD, Jung JE, Maestri CA, Carvalho NS. The role of P16ink4a and P53 immunostaining in predicting recurrence of $\mathrm{HG}$ -CIN after conization treatment. Rev Col Bras Cir. 2016;43(1):35-41.

27. Fu Y, Chen C, Feng S, Cheng X, Wang X, Xie X, et al. Residual disease and risk factors in patients with high-grade cervical intraepithelial neoplasia and positive margins after initial conization. Ther Clin Risk Manag. 2015;11:851-6.

28. de Mello Silva MV, Coutinho IC, de Andrade Heráclio S, Fittipaldi HM Jr, Katz L. Factors associated with the persistence/recurrence of CIN2/3 in women submitted to loop electrosurgical excision procedure in a teaching hospital in northeastern Brazil: a case-control study. J Low Genit Tract Dis. 2014;18(4):286-90.

29. Omori M, Hashi A, Nakazawa K, Yuminamochi T, Yamane T, Hirata $S$, et al. Estimation of prognoses for cervical intraepithelial neoplasia 2 by p16INK4a immunoexpression and high-risk HPV in situ hybridization signal types. Am J Clin Pathol. 2007;128(2):208-17.

30. Wang PH, Chen GD, Chang H, Yang SF, Han $C P$, Lin $L Y$, et al. High expression of human telomerase reverse transcriptase in high-grade intraepithelial neoplasia and carcinoma of uterine cervix and its correlation with human papillomavirus infection. Reprod Sci. 2007;14(4):338-48. 
31. Bravaccini S, Sanchini MA, Amadori A, Medri $L$, Saragoni L, Calistri D, et al. Potential of telomerase expression and activity in cervical specimens as a diagnostic tool. J Clin Pathol. 2005;58(9):911-4.

32. Wilkinson TM, Sykes PH, Simcock B, Petrich S. Recurrence of high-grade cervical abnormalities following conservative management of cervical intraepithelial neoplasia grade 2. Am J Obstet Gynecol. 2015;212(6):769.e1-7.
Received in: 11/08/2016

Accepted for publication: 26/09/2016

Conflict of interest: none.

Source of funding: none.

Mailing address:

Ana Paula Szezepaniak Goulart

E-mail: anapgoulart@hotmail.com

calpetry@ig.com.br 